\title{
Employee Relationship Management: Key to Organizational Growth
}

\author{
Sumesh Raizada \\ Professor, Jagan Institute of Management Studies, Institutional Area, Sector-5, Rohini, \\ Delhi (India)
}

Tel: 91-9650758671 E-mail: sumesh.raizada@jimsindia.org/aizadasumesh@yahoo.com

Received: April 5, 2019 Accepted: May 5, 2019 Published: June 20, 2019

doi:10.5296/bms.v10i1.14951ＵRL: https://doi.org/10.5296/bms.v10i1.14951

\begin{abstract}
Employee Relationship Management (ERM) is both a management philosophy as well as strategy, and is extremely vital for the success of business organizations nowadays. It emphasize on effective inter and intra departmental coordination thereby enhancing employee engagement, creativity and productivity. The present paper is conceptual. It shall discuss ERM and explore its relevance in improving the performance of an organization. Paper shall identify various factors that contribute towards measurement and analysis of ERM in the organizations. Attempt has been made to quantify the attributes, propose indices for measurement and explore their linkages with the organizational performance indicators. Paper shall also develop conceptual model and hypotheses related to ERM for further empirical study by researchers and academicians. Both online as well as offline information has been sourced through books and articles.
\end{abstract}

Keywords: Employee, Relationship, Management, Measurement, Analysis, Organization, Performance 


\section{Introduction}

In a global and competitive business environment, success of any commercial enterprise is primarily measured through its revenues and profits. These are largely dependent upon its profitable customers as well as cost effective channel partners. However, acquiring and retaining satisfied customers is extremely challenging for an organization. It has to consistently remain ahead of competition through innovative products, quality services and reasonable pricing besides nurturing enthusiastic and committed employees. Sincere, motivated and diligent employees contribute significantly towards converting a prospect into a buyer and consequently to a loyal \& repeat customer. Thus, cordial relationship among the employees and a healthy working environment is extremely vital for the organizational growth.

\section{Employee Relationship Management (ERM)}

i. “Always treat your employees exactly as you want them to treat your best customers" ...... Stephen R. Covey

ii. "Loyal Employees in any company create loyal customers, who in turn create happy shareholders”...... Richard Branson

iii. “At HCL Technologies we developed a management approach called Employees First, Customers Second that has become known around the world. It is not a human resources initiative, as many seem to assume. It's an employee satisfaction program. It is about employees, but it's not about HR ........ Vineet Nayar

The above quotes by management thinkers and business executives highlight the importance of employees and their vital contributions towards the success of an organization. It is essential that the employees work in a friendly environment so as to be more productive and innovative at workplace. This is largely possible when there is an understanding and co-ordination among the employees as well as between the employees and the management. Managing Employee Relations is not new to the organizations and has been in existence as a part of Industrial Relations or Human Resource Management. The difference is probably in the efforts being made to quantify the employee relations and associate them with customer satisfaction and overall organizational performance.

Similar to Customer Relationship Management, which measures customer satisfaction and profitability, Employee Relationship Management measures employee satisfaction and performance. It focusses on fostering long lasting mutually beneficial relationship among the employees, irrespective of their hierarchy.

ERM can be further described as the set of activities aimed at maintaining harmonious relationships among each and every employee so as to achieve organizational objectives. It is the management of activities aimed at enhancing employee performance while sustaining his integrity and loyalty to the organization. Regular ERM activities can lead to satisfied and motivated employees, which in turn would help in retaining loyal and profitable customers. 


\section{Macrothink}

Effective coordination between different departments can substantially increase productivity, minimize delays and curtail costs. Hence, keeping ERM index high is extremely significant for the organizations regardless of the industry in which they operate or the customer to whom they cater.

\section{ERM Initiatives}

Concept of ERM has been successfully applied since long in India, in the family controlled corporate houses and public sector undertakings such as Tata, Birla, BHEL and SBI. These organizations have controlled their businesses successfully by treating their employees as a family. They provide facilities such as housing, recreation, health care and education. Employees and their families socialize among themselves regularly. This develops strong personal bonding, cooperation and friendship, which is carried further to the workplace. References have been drawn from HCL Technologies and Tata Steel in India as well as Virgin Group internationally, where ERM has been successfully practiced.

\subsection{HCL Technologies}

HCL Technologies proved that with proper employee engagement, positive results can be achieved. As per Vineet Nayar, former CEO, following strategies were implemented during Employee First Customer Second initiatives, introduced in 2005;

- Mirror Mirror: Creating the need for change

- Trust through Transparency: Creating a culture of change

- Inverting the Organizational Pyramid: Building a structure for change

- $\quad$ Recasting the role of the CEO: Transferring the responsibility for change

Purpose of above was to bring about a transformational change in the culture and working of the organization, which was necessitated due to rapidly changing global business environment. An atmosphere of trust and transparency was created and feeling of job security was developed during tough times. Smart Response initiative was introduced seeking ideas and suggestions for improvements from the employees on an open online platform. Employees were supposed to rate their superiors and colleagues as well as those from the other related departments. CEO and senior management were made accountable for the projects. Employee first councils were formed which were virtual and in which employees participated according to their interest. It helped immensely in employee engagements and performance.

As an outcome of the above strategies, company in the first four years of the implementation (2005-2009) was able to increase its number of customer by five folds, reduce employee attrition by fifty percent, and improve employee satisfaction by seventy percent.

\subsection{Tata Steel}

Tata Steel grew several folds in last over a century, largely due to its numerous pioneering employee relations initiatives. Several policies initiated by it later became part of the 
Industrial law and also adopted by International labour Organization. Though many of these might be categorized under industrial relations or hygiene - motivation factors, but they all were built around Tata group strong culture of empowering its employees and imbibing a sense of trust and loyalty among them. Tata Steel consider its employees as its greatest asset and fosters an environment of aspirational goal setting, continuous improvement, health, safety and corporate responsibility. Employees participate in decision making and gets ample leadership opportunities through participation in quality improvement initiatives. Employees are treated fairly, with respect and honesty and are supported in achieving their goals. According to some of its former employees, company has excellent work culture, best ethics policies, less stress, cooperative and friendly work environment, opportunity for career growth and learning for the deserving ones and a decent work life balance.

\subsection{Virgin Group}

Employees are considered to be the most important stakeholder followed by customers and shareholders, in the Virgin group. According to Richard Branson, companies co-founder, 'Happy Employees equal Happy Customers. Similarly, an unhappy employee can ruin the brand experience for not just one, but numerous customers'. He believes that 'If the person who works at your company is not appreciated, they are not going to do things with a smile'. The group has taken several policy measures for its employees to keep them committed to the organization. They have freedom to make important decisions and have a sense of ownership over what they are doing. Every employee is made familiar with the corporate culture of the organization and these values are nurtured regularly through workshops, meetings and seminars. Employees are involved by seeking their suggestions and making them feel part of the company. They are treated as distinct individuals with different set of problems or needs and hence are treated separately by providing them flexibility of leaves and work timings.

\section{Scope and Significance of ERM}

ERM lays emphasis on developing close interpersonal relationships at workplace. It is therefore highly relevant in organizations where employees work in team or are dependent upon others for the success of a project. However, it may not work so well in those organizations that follow bureaucratic culture with formalized organizational hierarchies and divisions among the employees. It might also not succeed in mining, construction or heavy engineering firms in which workers are semi-literate and are not involved in the decision making. ERM initiatives may be ineffective in work culture where departments, offices, manufacturing units or managers operate in silos.

ERM can be successfully implemented in service industries having direct customer interface, such as Banking, Insurance, Retail, Hospitality, Aviation, Utilities and IT-ITeS. It shall also be effective in the industrial product and business marketing firms in which quality of customer service is extremely important for their survival and growth. ERM contributes to better understanding of job roles and responsibilities as well as transparency among the team members. This leads to strong coordination and successful target completion, consistently. 


\section{Al Macrothink}

ERM plays an important role in employee motivation, engagement and performance in the organizations. It also helps in reducing attrition especially among the high performers thereby minimizing the costs of recruitment, training and development. In view of high acquisition costs and global competition, retaining satisfied and loyal employees has become a necessity for the corporate, nowadays. Those organizations which practice ERM in some formal or informal ways, definitely experience less conflicts among employees or between employees and management. This creates a good image of the organization among other stakeholders such as customers, business partners, investors and potential employees. In ERM, efforts are to retain the profitable employees and to convert non-profitable into the profitable ones. It requires changing the mind-sets and work culture with the active participation and initiative of top management as well each employee of the organization.

All the above factors combined together, contributes largely to the cost savings, increase in revenues, profits and market share, which in turn leads to higher returns to the investors and rewards to the employees.

\section{ERM Strategies}

'Take care of your employees and they will take care of your customers'. Many organizations believe in this philosophy to improve their top and bottom lines. However this does not mean that employees need to be given additional perks or incentives. Some of the initiatives for Employee Relationship Management, are listed as follows;

- Empowering the employees to take decisions in the best interest of the company

- Providing autonomy and freedom in their domain of work and making them collectively responsible for achieving the targets

- Inculcating transparency and trust among the team members and across departments and functional areas

- Encouraging cooperation and support between various departments treating each other as the internal customer

- Minimizing delays and wastages of resources including time, money and efforts, through effective coordination

- Encouraging creative ideas for the growth and improvement within the work domain through Quality Circles, SGIA, TQM and Kaizan

- Clarity in the role and responsibilities of each employee and assigning tasks according to skills, expertise and experience

- Providing mentorship to the slow movers or those who are new to the organization

- Treating co-workers as a family member and providing them moral, emotional and physical support whenever required

- Respecting employee privacy, not intruding into their personal zone and valuing them for their achievements

- Engaging employees in social, cultural and creative activities to relieve them from workplace stresses, thereby rejuvenating their energy and enthusiasm

- Sharing of the accurate information quickly and consistently among team members or 
concerned departments

- Treating customer's query, complaint or project completion deadlines as a joint responsibility of all rather than of only the marketing, services or operations team

- Regularly disseminating and discussing management plans and policies

- Ensuring cleaner and safer work environment

- Strictly enforcing ethical code of conduct and encouraging employees to maintain integrity and honesty

The above listed measures are the responsibility of each and every employee irrespective of her job role or position. Relationship between the co-workers must go beyond the workplace to family outings, clubs, gyms, etc. When bonding is strong and beyond professional rivalries, cooperation improves and tasks are achieved without stress and conflicts. Then, departmental colleagues no longer remain the competitors rather they become associates.

To some extent ERM is a concept which emanates from industrial relations of pre-liberalization period and HRM of present era of globalization, combined with internal and relationship marketing. Critical issues are identified and resolved by pooling suggestions from the co-workers through open discussions. Ultimate objective is to achieve consistent and profitable growth of the organization.

\section{Measurement and Analysis of ERM}

\subsection{Measurement}

Some of the key attributes in measuring the effectiveness of Employee Relationship Management, have been identified as follows;

- $\quad$ Attrition, Retention and Loyalty

- Productivity and Profitability

- Performance target achievement

- Career growth and Empowerment

- Social and Cultural immersion

- Communication \& Involvement in decision making

- Employee Satisfaction

These attributes are being measured through proposed indices. Their linkages with the organizational performance indicators are also being deliberated

\section{Assumptions}

For computational purpose, hypothetical figures have been taken for various performance indicators. The given ERM indices are to be measured on annual basis, at the end of each financial year.

\subsubsection{Employee Loyalty Index (ELI)}

It indicates the work culture, company policies and employee satisfaction. This index may be 
debatable in reference to public sector undertakings or government enterprises, where employees simply don't leave the organization due to job security or complacency. It shall range between 0 and 1

Employee Loyalty Index (ELI) $=$ [Sum of total employment of all the employees in years (X)] / [Total number of Employees in the organization $(\mathrm{Y}) *$ Number of years since organization was established $(\mathrm{N})]$

Employees having less than one year of service are not included

Suppose; $\mathrm{X}=250, \mathrm{Y}=50, \mathrm{~N}=20$

Then, ELI $=250 /(50 * 20)=0.25$

Ideally it should be close to ' 1 ', indicating that all employees are working since the company was established. However, in old organizations, employees retire, move elsewhere or may not be working since its inception. Similarly for new organizations, recruitment regularly takes place as the company grows. Hence number of employees initially may be too less compared to those who joined later. Scores close to ' 0 ', indicate that either employee attrition is too high or company is too old. For a young company, low scores indicate dissatisfaction with its policies or work culture.

\subsubsection{Employees Profitability Index (EPR)}

It measures yearly growth in total gross profits against annual rise in the total costs incurred on all the employees of the organization. It finds out if the organization is growing in proportion to the increase in number of employees or their cost to the company.

Employee Profitability Index $(\mathrm{EPR})=$ Annual growth in Gross Profits over last year (X) / Annual increase in CTC of all the employees over last year (Y)

CTC - Cost to the Company, which includes salary, perks and other facilities (in monetary value) provided to the employees

Suppose;

Gross Profits (Current Year) $=$ Rs.500000

Gross Profits (Last Year) $=$ Rs.400000

Total annual CTC of all the employees (Current year) $=$ Rs.2000000

Total annual CTC of all the employees (Last Year) = Rs.1500000

$X=500000-400000 / 400000=100000 / 400000=0.25$

$\mathrm{Y}=2000000-1500000 / 1500000=500000 / 1500000=0.33$

Then, EPR $=0.25 / 0.33=0.75$

It should ideally be positive and more than ' 1 '. Higher index denotes that profits are 
increasing at a faster rate compared to the employees cost. On the other hand EPR less than ' 1 ' indicates that employee costs are rising more as compared to profits. Negative index means either a drop in the annual gross profits or in the CTC compared to the previous year. Fall in annual CTC could also be either due to reduction in staff or drop in compensation package. All these may be attributed to the poor financial health of the firm.

\subsubsection{Employee Performance index (EPF)}

Employees level of motivation and capabilities to a large extent are assessed by their actual achievements compared to the annual budgeted targets. However, these may not always reflect the sincerity and efforts put in by them. There could also be uncontrollable environmental factors, which might affect their performance output. Limitation of this method is that all employees may not be having the quantifiable budgets for the year. Marketing, customer service or operation teams generally have quantifiable budgets, while clerical, personnel, accounts or administrative staff don't have. For the simplicity, the overall budgeted and actual achievement of the firm are being considered.

Employee Performance index $(\mathrm{EPF})=$ Actual Achievement $(\mathrm{X})$ / Budgeted Quantifiable Targets (Y)

\section{Suppose;}

Actual Sales for the financial year $(\mathrm{X})=$ Rs.3000000

Budgeted Sales for the financial year $(\mathrm{Y})=$ Rs.2500000

Then, $\mathrm{EPF}=3000000 / 2500000=1.2$

Ideally it should be ' 1 ' or above indicating that actual performance is meeting or exceeding the annual budgeted targets. High variance on positive side however is not appropriate, as it shows poor budgetary planning. Ratio of less than unity would suggest shortfall in the achievement, which could be due to non-performance by the team members. Moreover, the shortfall may also be due to delays in raw material from the suppliers, rejections by the customers, damages during transportation or changes in the taxation policy, for which employees may not be held responsible.

\subsubsection{Career Progression Index (CPI)}

Career progression refers to employee's advancement in terms of hike in compensation, change in designation or enhancement in job responsibilities.

Career Progression Index $(\mathrm{CPI})=$ Number of employees with career progression during the year (X) / Total number of employees (Y)

Suppose; $\mathrm{X}=5$ and $\mathrm{Y}=50$

Then, $\quad$ CPI $=5 / 50=0.10$

Ideally, it should be ' 1 ' that is all the employees getting advancement in their jobs, but not 
practically possible. Higher index indicates that the organization is progressing and more growth opportunities are being created for the employees.

\subsubsection{Social Index (SI)}

It suggests the employee participation in social and cultural activities, held outside their workplace during the year. The events may or may not include their family members. These may be celebration of festivals, outdoor excursion, sports or social services. Such activities helps in building close interpersonal relationship among the office colleagues who otherwise are unable to do so during their busy work schedule.

Social Index (SI) = Total number of employees participation in all the social events held (X) /

[Total number of social events held during the year $(\mathrm{N}) *$ Total number of Employees $(\mathrm{Y})$ ]

Suppose; $\mathrm{X}=125, \mathrm{~N}=5, \mathrm{Y}=50$

Then, SI $=125 /[5 * 50]=125 / 250=0.50$

Though practically difficult, it should ideally be close to ' 1 ', which indicates that all the employees have participated in every event. Higher participation in such activities provides likelihood of close personal interaction among the employees outside their work environment. On the other hand, SI close to '0' reflects possibility of poor inter-personal bonding. It could be due to professional rivalries, personal issues or lack of emotional attachment with the organization.

\subsubsection{Communication Index (CI)}

It specifies the formal communications held at workplace during the year, in which employees discusses new ideas or improvements in their work domain. These could be personal or virtual meetings, online discussion forums, group mails, newsletters, messages, quality circles and TQM activities. Higher number shows healthy coordination and exchange of creative ideas among employees. These are not the budget review meetings or those concerned with employee grievances and disputes. Besides, casual communications outside workplace are not included in this.

Communication Index $(\mathrm{CI})=$ Sum of all the employees who participated in each formal communication $(\mathrm{X}) /$ [Total number of formal communications held during the year $(\mathrm{N})$ * Total number of employees (Y)]

$\mathrm{N}$ : Total number of formal meetings or discussions held face to face or virtually, in a year to deliberate on the improvements at workplace, to brainstorm on critical issues, to encourage creative ideas, to find solutions of technical problems or to explore ways of increasing the productivity

Suppose, $\mathrm{X}=400, \mathrm{~N}=12, \mathrm{Y}=50$

Then, $\mathrm{CI}=400 /[12 * 50]=400 / 600=0.66$ 
Once again the index should be close to ' 1 ', which denotes that large number of employees participate in creative discussions and problem solving. It is expected that such interactions involve employee at all levels of hierarchy, departments and functional areas. Values nearer to ' 0 ' convey limited communication and formal interaction among the employees.

\subsubsection{Employee Satisfaction Index (ESI)}

A good performer in an organization is usually sincere, diligent and socially active. Yet she may be dissatisfied with the work culture, policies, colleagues or work-life balance. This index helps in identifying the areas of concern and should be tackled at the earliest before the disgruntled employees turn non-profitable, frustrate others or leave the organization. ESI can be measured by averaging the Satisfaction score (Ss) of all the employees.

Employee Satisfaction Index $(\mathrm{ESI})=\left(\mathrm{Ss}_{1}+\mathrm{Ss}_{2}+\mathrm{Ss}_{3}+\ldots . . \mathrm{Ss}_{\mathrm{N}}\right) / \mathrm{N}=\sum \mathrm{Ss} / \mathrm{N}$

Where, Ss: Satisfaction Score of individual employee; and N: The total number of employees

Satisfaction score (Ss) for individual employee is computed as sum of ratings of three key parameters on a 5 point scale divided by maximum combined rating of all the three parameters

$$
\mathrm{Ss}=(\mathrm{S} 1+\mathrm{S} 2+\mathrm{S} 3) / 15
$$

Where;

S1: Satisfaction with Policies and Culture of the organization (Work Environment, Code of Conduct, etc.)

S2: Satisfaction with Superiors (Supportive, Motivating, Transparent, Authoritative, Short tempered, Mild, Knowledgeable, etc.)

S3: Satisfaction with Colleagues and Subordinates (Cooperative, Inefficient, Team player, etc.)

Above parameters are to be rated by each employee on a scale of 1 to 5, where;

\section{1: Highly Dissatisfied, 2: Satisfied, 3: Can't Say, 4: Satisfied and 5: Highly Satisfied}

Suppose an Employee (x) gives rating of above satisfaction parameters as;

$\mathrm{S} 1=3, \mathrm{~S} 2=4, \mathrm{~S} 3=5$, then putting values in Equation (ii)

$$
\mathrm{Ss}_{\mathrm{x}}=(3+4+5) / 15=12 / 15=0.8
$$

Similarly, Ss1, Ss2 and upto SsN can be worked out for each employee, separately

By putting these values in equation (i) above, ESI index shall be computed for all the employees

For example, in an organization; If, sum of Satisfaction score of all the 50 employees $\sum \mathrm{Ss}=$ 35 and Total number of Employees $\mathrm{N}=50$ 
Then, ESI $=\sum \mathrm{Ss} / \mathrm{N}=35 / 50=0.7$

In this case, score above 0.6 and upto 0.8 should be considered as satisfactory while that above 0.8 as good. However, score of 0.6 or below implies that employees are dissatisfied on one or more satisfaction parameters.

\subsubsection{Composite ERM Index (EI)}

This consolidates the various sub-indices of ERM into a composite index. It is to be measured as an arithmetic Mean of all the above seven indices, discussed in the section 6.1.1 to 6.1.7

Thus, EI $=\Sigma($ ELI, EPR, EPF, CPI, SI, CI, ESI) $/ 7$

Putting computed values of the respective indices from section 6.1.1 to 6.1.7, in the above equation;

$\mathrm{EI}=(0.25+0.75+1.20+0.10+0.50+0.66+0.70) / 7=0.59$

Values nearer to ' 1 ' indicate better ERM initiatives and practices in the organization, while those close to ' 0 ' convey low employee participation, poor morale and interpersonal relationships.

\subsection{Analysis}

Effectiveness of ERM efforts can be corroborated through organization's annual performance in terms of revenue growth, profits, employee attrition, customer satisfaction and market share. Graphs can be prepared on the basis of yearly data, to assess the efficacy of ERM.

Though to be empirically tested, it is presumed that EI would have positive correlation with all except the employee attrition, with which it would have negative correlation. The yearly movement of ERM and few performance indicators are depicted in Figure 1, on the basis of assumed data.

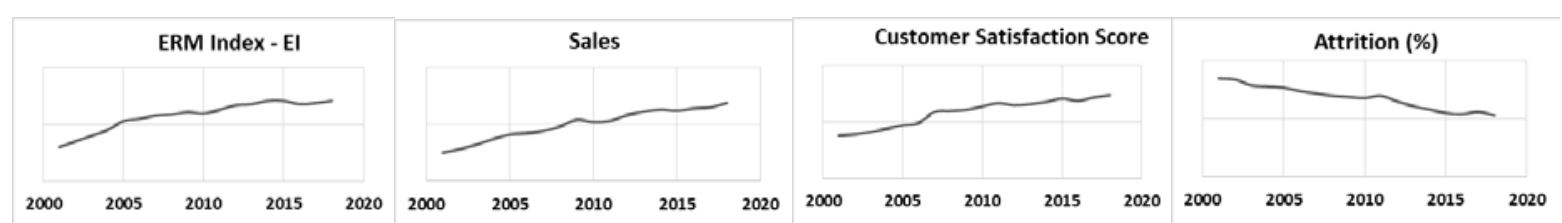

Figure 1. Yearly movement of ERM index and key Performance indicators

The above indicators of ERM have been estimated for a small organization having 50 employees. These indices can be similarly measured for large organizations, separately for different SBUs, manufacturing units or branch sales offices.

\section{Conclusions}

Employee Relationship Management (ERM) is extremely important in organizations especially those in which employees come from different nationalities and cultural backgrounds. Companies need to have a common code of conduct, organizational culture and 


\section{Macrothink}

workplace ethics, which would help them in binding their employees together as a family. The best way is to implement the ERM practices and measuring them on annual basis.

Through the above hypothetical study, an effort has been made to quantify Employee Relationship Management at the workplace and its impact on the overall performance of an organization or a particular department. However, these have to be validated empirically in the organizations across different industry sectors.

It is assumed that computed indices would vary depending upon, whether the organization is; Private or Government, Services or Manufacturing, Domestic or Multinational, has White collared or Blue collared employees, and whether practicing Contemporary or Conventional management styles.

\subsection{ERM Cycle}

Since Customer Relationship Management (CRM) is very closely linked to ERM, the concept is being described in terms of ERM cycle (refer Figure 2).

Harmonious work environment and better interpersonal coordination contributes to higher ERM as well as enhanced motivation and satisfaction level. This in turn improves the quality of services provided to the customer and leads to enhancement in CRM. This further results in customer loyalty, repeat purchases and profitability for the firm. Due to improvement in performances, employees get rewarded and gets further motivated to perform well. Thus cycle gets repeated, contributing to continuity in the performance of the employees.

\section{ERM CYCLE}

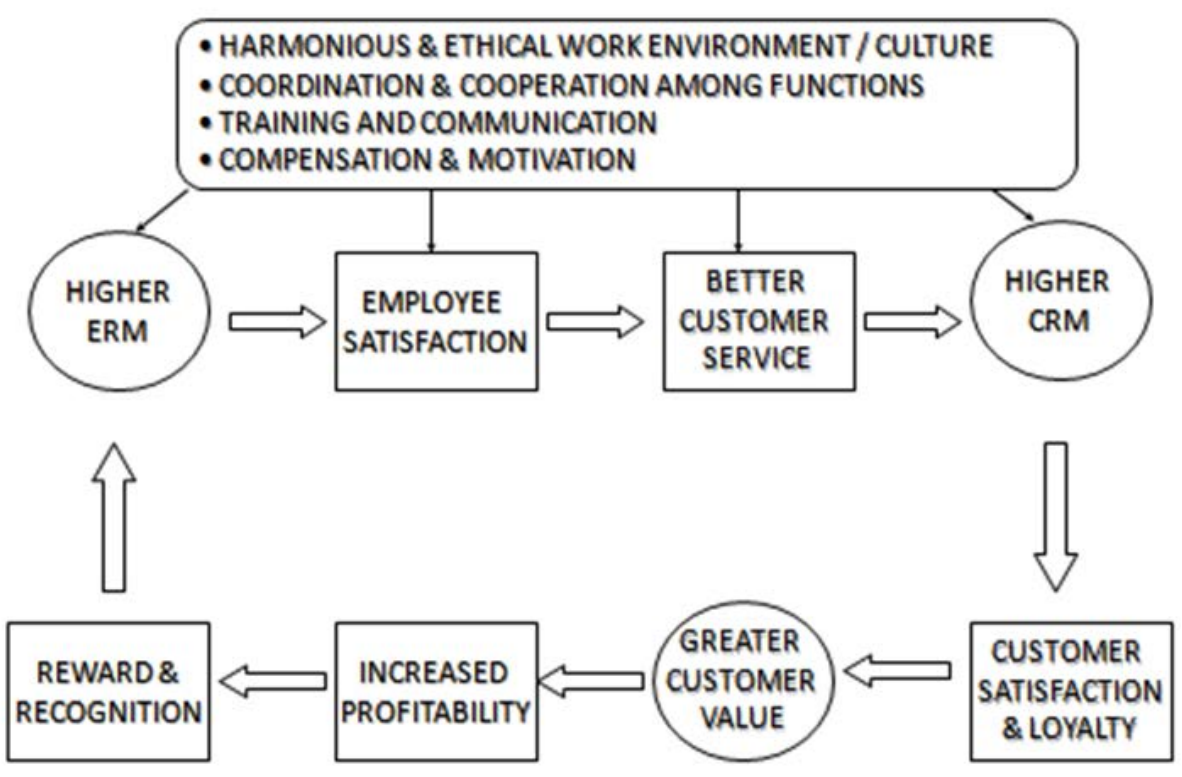

Figure 2. ERM Cycle

Source: Author 
Organizations can augment their ERM indices through following approaches;

\subsection{Improving ERM}

1) An online social group or community may be created in which employees interact, chat and discuss informally on various issues, seek advice on problems and post their achievements and experiences.

2) At least once in a quarter, social, cultural or sport activities may be organized, involving all the employees and their families. Important stakeholders may also be invited and honoured in few such gatherings.

3) Small groups may be established in each department, to suggest innovative ideas and solutions related to work procedures, reduction in expenses and increase in the productivity.

4) A designated space and facility for common lunch and recreation can be provided. This can considerably reduce the communication gap existing between the co-workers.

5) If suggestion given by an employee or group are implemented, it should be acknowledged and publicized in the internal communication to the employees. Best ideas should be rewarded on quarterly basis.

Organizations should improve their ERM, to retain motivated and competent employees, who in turn would contribute to their long term sustainable growth.

\section{References}

Branson, R. (2019). What employee wellbeing means to me. [Online] Available: https://www.virgin.com/disruptors/what-employee-wellbeing-means-me-richard-branson (March 3, 2019)

Godson, M. (2009). Relationship Marketing, Oxford University Press, Delhi, 268-295.

Heathfield, S. M. (2019). Top 10 Reasons Why Employees Quit Their Jobs-A Checklist for the Retention of Your Talented Employees [Online] Available: https://www.thebalancecareers.com/top-reasons-why-employees-quit-their-job-1918985 (February 28, 2019)

HR practices in Tata Steel. [Online] Available: https://www.tatasteel.com/sustainability/sustainability-pillars/hr-practices/ (March 3, 2019) Jill, D. (2007). The CRM Handbook, Pearson Education, New Delhi.

Kotler, P., \& Keller, K. L. (2005). Marketing Management (12th ed.). Upper Saddle River, NJ: Pearson Prentice Hall

Kunsman, T. (2019). Internal Marketing: Why Your Company Should Prioritize It [Online] Available: https://everyonesocial.com/blog/internal-marketing/ (February 21, 2019)

Leigh, R. (2019). What is Employee Relationship Management? [Online] Available: 


\section{Macrothink}

https://smallbusiness.chron.com/employee-relationship-management-709.html (February 22, 2019)

Mukerjee, K. (2009). Customer Relationship Management - A Strategic Approach to Marketing, PHI Learning, Delhi

Nayar, Vi. (2019). Why I put my employees ahead of my Customers [Online] Available: https://www.forbes.com/2010/06/18/employees-first-vineet-nayar-leadership-managing-hcl.ht ml\#2e4a9cc54e81 (February 18, 2019)

Nayar, V. (2010). Employee First Customer Second, Harvard Business Press, Bostan.

Raizada, S. (2011). Engage from Within, Indian Management, March 2011, 14-24.

Schwantes, M. (2019). Why Are Your Employees Quitting? A Study Says It Comes Down to Any of These 6 Reasons [Online] Available: https://www.inc.com/marcel-schwantes/why-are-your-employees-quitting-a-study-says-it-co mes-down-to-any-of-these-6-reasons.html (February 28, 2019)

\section{Copyright Disclaimer}

Copyright for this article is retained by the author, with first publication rights granted to the journal.

This is an open-access article distributed under the terms and conditions of the Creative Commons Attribution license (http://creativecommons.org/licenses/by/3.0/). 